BELTRAME, R.T., FERNANDES, D.R. e QUIRINO, C.R. Utilização do ultra-som em tempo real na avaliação da carcaça de pequenos ruminantes. PUBVET, Londrina, V. 5, N. 3, Ed. 150, Art. 1008, 2011.

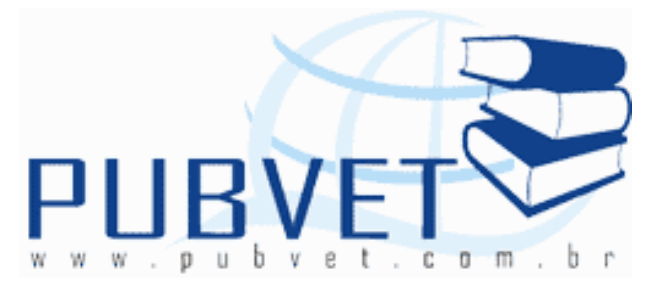

PUBVET, Publicações em Medicina Veterinária e Zootecnia.

\title{
Utilização do ultra-som em tempo real na avaliação da carcaça de pequenos ruminantes
}

Renato Travassos Beltrame ${ }^{1}$, Danieli Rankel Fernandes ${ }^{2}$, Celia Raquel Quirino ${ }^{3}$

1 Doutor em Ciência Animal, Professor - UNESC - Colatina - ES. rtbeltrame@yahoo.com.br

${ }^{2}$ Médica Veterinária, Mestranda em Ciências Veterinarias

3 Doutora em Ciência Animal - Professora Associada - Laboratório de Reprodução e Melhoramento Genético Animal - CCTA - UENF.

\section{Resumo}

A utilização de equipamentos de imagem na produção animal não é recente sendo o ultra-som um método seguro não existindo efeitos deletérios ao individuo, gestantes e fetos. A utilização deste equipamento tem se direcionado aos estudos reprodutivos, de desempenho dos grupos genéticos, nutrição e qualidade da carcaça na espécie ovina e caprina. Neste sentido, nesta revisão serão discutidas a formação da imagem de ultra-som e a aplicação desta técnica na produção de pequenos ruminantes.

Palavras-chave: carcaça, biometria, area de olho de lombo. 
BELTRAME, R.T., FERNANDES, D.R. e QUIRINO, C.R. Utilização do ultra-som em tempo real na avaliação da carcaça de pequenos ruminantes. PUBVET, Londrina, V. 5, N. 3, Ed. 150, Art. 1008, 2011.

\title{
Use of ultrasound in real-time assessment to small ruminant carcass evaluation
}

\begin{abstract}
The use of ultrasound image in animal production is not new, being a safe method in the absence of deleterious effects to the individual, pregnant female and fetuses. The use of this equipment has been directed to study the reproductive status, performance of genetic groups, nutrition and carcass quality in sheep and goats. In this sense, this review will discuss the formation of the ultrasound image and the application of this technique in small ruminant production.
\end{abstract}

Keywords: carcass, biometry, ribeye

\section{1 - Introdução}

A produtividade da ovinocultura ainda é considerada baixa, principalmente em decorrência de sistemas de alimentação deficientes, especialmente nos períodos críticos, da baixa qualidade genética dos rebanhos, de problemas sanitários e de manejo reprodutivo ineficiente. Embora se tenha visualizado uma grande evolução nos últimos anos, as atividades pertinentes aos pequenos ruminantes permanecem estagnadas pelos gargalos tecnológicos que traduzem ao mercado uma oferta de carne precária confirmada por um fornecimento sazonal e abates tardios, comprometendo a qualidade das carcaças e limitando o acesso aos principais canais de comercialização, frigoríficos e supermercados (SUGUISAWA et al, 2009).

A ultra-sonografia do aparelho reprodutor da ovelha e da cabra tornou-se um procedimento de rotina em rebanhos superiores, intencionando não só auxiliar no manejo dos animais, mas principalmente na melhoria da eficiência reprodutiva nos últimos anos (HAIBEL, 1990; GANAIE et al, 2009).

Em adicional, o estudo da composição de carcaça através da avaliação da área do músculo Longissimus toracicus et lumborum (longissimus dorsi) e da 
BELTRAME, R.T., FERNANDES, D.R. e QUIRINO, C.R. Utilização do ultra-som em tempo real na avaliação da carcaça de pequenos ruminantes. PUBVET, Londrina, V. 5, N. 3, Ed. 150, Art. $1008,2011$.

espessura de gordura subcutânea, mensuráveis através da ultra-sonografia in vivo nos pequenos ruminantes tem auxiliado na avaliação genética de reprodutores ovinos (HOPKINS et al, 2007). Apesar disto tais predições estão sujeitas invariavelmente a precisão das medidas obtidas que, uma vez aplicadas, influenciam o resultado da predição da composição corporal.

Diante do descrito esta revisão foi desenvolvida para abordar os aspectos da formação da imagem ultra-sonográfica e seu uso na avaliação da carcaça de pequenos ruminantes.

\section{2- Bases para formação da imagem do ultra-som}

A detecção de altas freqüências emitidas pelo ultra-som não é realizada pelo ouvido humano. Quando o transdutor do ultra-som é colocado sobre a pele ou a mucosa, através da qual um exame é efetuado, os sons emitidos refletem-se nos órgãos e estruturas internas do paciente, retornando como ecos sonoros que são recebidos pelo mesmo transdutor. Estes ecos (ondas de sons), que não afetam de forma negativa o organismo, são eletronicamente modificados e transformados em imagens de tempo real apreciadas na tela de um monitor de forma imediata (SANTOS et al, 2004; NYLAND \& MATTOON, 2004; DESCOTEAUX et al, 2010).

A depender do equipamento, um transdutor de um ultra-som pode emitir ondas de uma única ou de múltiplas freqüências. Cabe ao ultrasonografista escolher a freqüência ideal do transdutor, que possibilite maior acurácia e precisão em relação à região anatômica a ser examinada. Na medicina veterinária são utilizados transdutores setoriais e convexos variando preferencialmente entre 3,5 e 8 megahertz (MHz) (Figuras 1,2 e 3) (WOLF et al., 2002; FERRI et al., 2003; NYLAND \& MATTOON, 2004). 
BELTRAME, R.T., FERNANDES, D.R. e QUIRINO, C.R. Utilização do ultra-som em tempo real na avaliação da carcaça de pequenos ruminantes. PUBVET, Londrina, V. 5, N. 3, Ed. 150, Art. 1008, 2011.
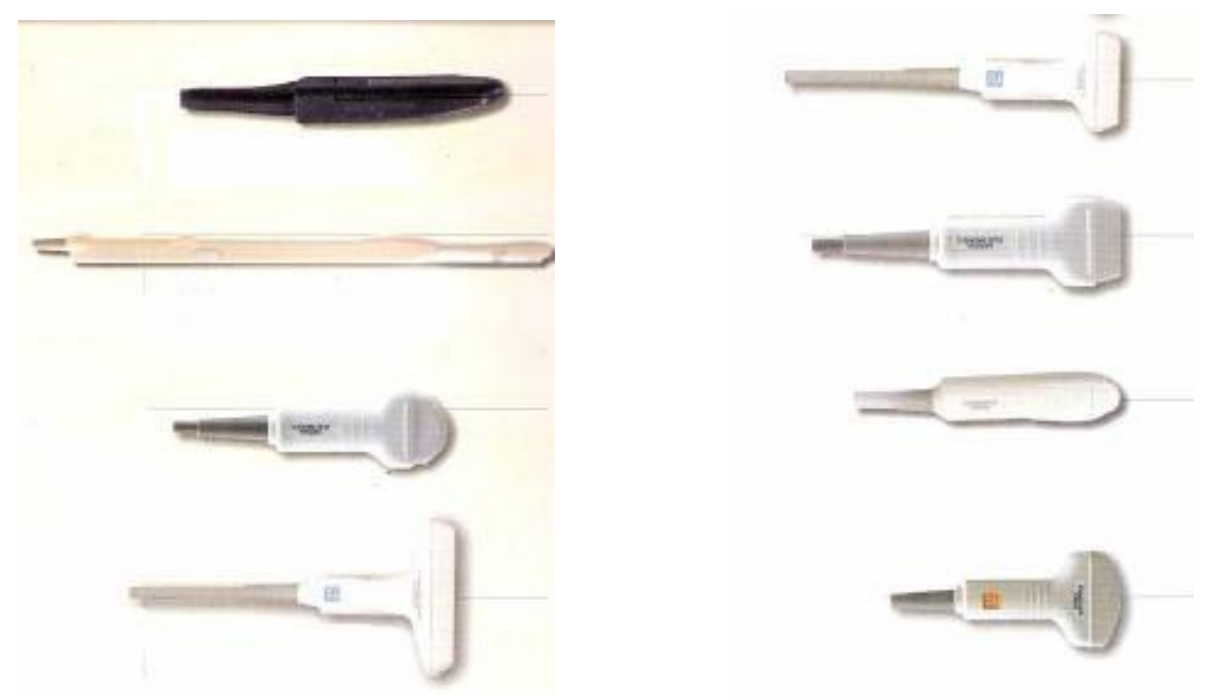

Figura 1. Transdutores setoriais e lineares utilizados na ultra-sonografia veterinária

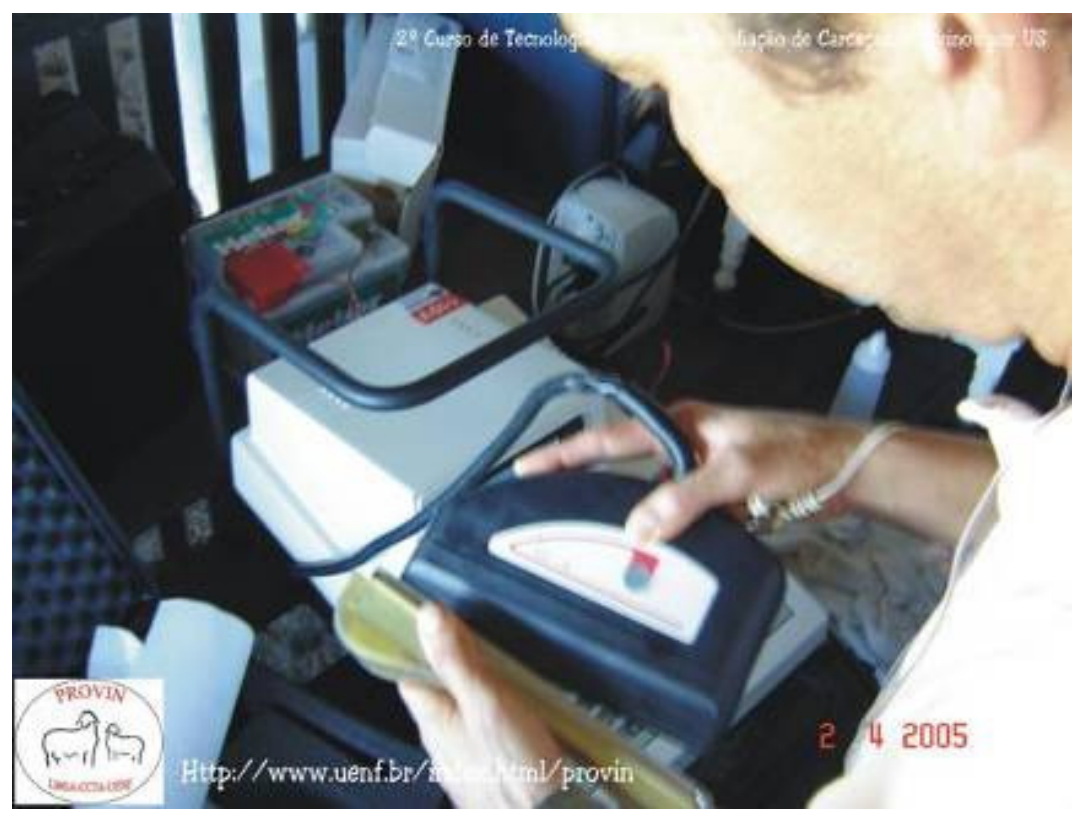

Figura 2. Transdutor utilizado para avaliação de carcaça bovina.

Em relação aos transdutores, aqueles com maior freqüência produzem imagens de alta resolução e menor penetração (> $5 \mathrm{MHz}$ ). Quando é 
BELTRAME, R.T., FERNANDES, D.R. e QUIRINO, C.R. Utilização do ultra-som em tempo real na avaliação da carcaça de pequenos ruminantes. PUBVET, Londrina, V. 5, N. 3, Ed. 150, Art. 1008, 2011.

necessária maior penetração, como acontece com a ultra-sonografia abdominal e algumas carcaças, os transdutores têm menor freqüência (convexos, setoriais), sendo igual ou inferiores a $5 \mathrm{MHz}$ (NYLAND \& MATTOON, 2004).

A freqüência é definida como o número de vezes que uma onda é repetida (ciclos) por segundo. Comprimento de onda é a distância que a onda percorre durante um ciclo. Quanto menor o comprimento de onda melhor a resolução da imagem. Uma vez que a velocidade do som é independente da freqüência, e praticamente constante nos tecidos moles do corpo, selecionar um transdutor de freqüência mais alta causa diminuição do comprimento de onda sonora emitido, o que propicia melhor resolução (NYLAND \& MATTOON, 2004).

Os equipamentos de ultra-som pressupõem uma velocidade do som constante em tecidos moles, embora exista uma pequena diferença. No entanto, quando o feixe encontra gás ou osso, ocorrem diferenças marcantes de velocidade que resultam em forte reflexão e interpretação inadequada dos ecos. Esta forte reflexão é decorrente da combinação de uma mudança abrupta na velocidade do som e da densidade do meio (impedância acústica) em uma interface osso-tecido mole, ou ar-tecido mole (NYLAND \& MATTOON, 2004; SANTOS et al., 2004; ARIAS et al., 2006).

Os princípios da US se baseiam na habilidade de diferentes tecidos em refletir ondas sonoras de altas freqüências. O transdutor é composto por cristais com propriedades piezoelétricas, responsáveis pela emissão das ondas ultra-sônicas e pela captação das ondas refletidas. O sistema de ultrasonografia em tempo real emite ondas sonoras (eco) de alta freqüência que são refletidas pelas várias interfaces dos tecidos. Estas são recebidas pelo transdutor (caracterizando impedância acústica diferente) e convertidas em energia elétrica, sendo exibidas no monitor com várias tonalidades da cor cinza (SANTOS et al, 2004).

$\mathrm{Na}$ passagem de uma onda ultrasonográfica por um tecido, parte é refletida na forma de um eco e parte prossegue interagindo com tecidos mais profundos. Estruturas anecóicas (p.ex. líquidos) não refletem as ondas e 
BELTRAME, R.T., FERNANDES, D.R. e QUIRINO, C.R. Utilização do ultra-som em tempo real na avaliação da carcaça de pequenos ruminantes. PUBVET, Londrina, V. 5, N. 3, Ed. 150, Art. 1008, 2011.

aparecem como áreas negras na imagem. Tecidos hiperecóicos (ossos) refletem grande parte das ondas e aparecem como áreas brancas. A denominação hipoecóica reflete imagens de maior ou menor intensidade variando nas tonalidades da cor cinza (SANTOS et al., 2004). As imagens são traduzidas em duas dimensões, permitindo identificar, órgãos, vesículas embrionárias, placentomas, movimentos fetais, fluidos, batimentos cardíacos maternos e fetais, músculos, gordura, dentre outros (BREUKELMAN et al., 2005; DESCÔTEAUX et al., 2010).

\section{3 - Avaliação de carcaças}

A avaliação da carcaça por predição in vivo visa garantir a eficiência do processo produtivo, possibilitando determinar o grau de terminação e de desenvolvimento muscular dos animais (ROSA et al., 2005),

Embora grande parte desta avaliação seja feita por observação visual e palpação, a presença de erros e divergências, em função do subjetivismo são freqüentemente relatados (SILVA SOBRINHO, 2001). No entanto, modernas técnicas, como as medidas obtidas por ultra-sonografia têm se destacado por apresentar alta repetibilidade. Além disso, destacam-se a capacidade de ser utilizada em animais vivos, rapidez, não invasiva, não apresenta riscos a saúde e oferece uma predição da carne magra e gordura na carcaça a custo aceitável, se considerarmos o incremento da produção e da qualidade da carne ovina (TAROUCO, 2003). CARR et al. (2002), destaca a possibilidade de estimar características de carcaça antes do abate, identificar animais que estejam se aproximando do ponto ótimo de acabamento e o auxílio em programas de melhoramento genético como as principais vantagens do uso do ultra-som em rebanhos ovinos.

Uma série de pesquisas têm sido realizadas para determinar correlações entre as medidas tomadas em tempo real (in vivo) e após o abate (post mortem) e para estimar equações de predição para cada genótipo de ovinos. Estas pesquisas objetivam reduzir os erros em comparações entre as raças e 
BELTRAME, R.T., FERNANDES, D.R. e QUIRINO, C.R. Utilização do ultra-som em tempo real na avaliação da carcaça de pequenos ruminantes. PUBVET, Londrina, V. 5, N. 3, Ed. 150, Art. 1008, 2011.

animais com diferentes pesos (FERNANDEZ et al., 1997; FERNANDEZ et al., 1998; LANDIN 2005; CARTAXO, 2006).

Nos estudos com bovinos, diversos trabalhos avaliaram a eficiência da utilização da ultra-sonografia em tempo real na predição da quantidade e percentagem de carne comercializável (SUGUISAWA et 2003; POLIZEL NETO et $A L, 2009)$. Estes autores concluíram que os modelos de predição baseados nas medidas obtidas por US apresentam uma acurácia similar se comparadas as medidas de carcaças post-mortem.

$\mathrm{Na}$ espécie ovina os trabalhos não caminham para comportamento diferente. As bases de utilização da ultra-sonografia em ovinos e caprinos obedecem aos mesmos padrões estipulados por bovinos, sendo esta técnica aplicada em estudos de grupos genéticos, nutrição e qualidade da carcaça e carne (SILVA et al, 2007; HOPKINS et al, 2008; SUGUISAWA et al, 2009). Diversos estudos vêm sendo conduzidos com o objetivo de avaliar a possibilidade de uso rotineiro da ultra-sonografia como um método de avaliação indireta da carcaça. Stanford, Jones, and Price (1998) publicaram uma revisão acerca de métodos para predizer a composição da carcaça em cordeiros com referência ao uso da ultra-sonografia para o estudo desta característica em ovinos.

A mensuração da espessura da gordura subcutânea (EGS) e a medida da área e da altura da seç̧ão do músculo longissimus dorsi, demonstrado na figura 3 , tomadas entre a $12^{a}$ e a $13^{a}$ costelas, constituem as principais características avaliadas pelo ultra-som na carcaça. Estas apresentam boa correlação com o teor total de gordura e com a proporção de músculo na carcaça, respectivamente. A utilização deste músculo deve-se a maturação tardia e a fácil mensuração, estimando com confiabilidade o desenvolvimento muscular do animal (SAINZ, 1996). À medida que o animal cresce, acontecem modificações nas suas proporções corporais. Sabe-se que o preenchimento da deposição de EGS ocorre das extremidades cranial/caudal para o centro da carcaça, sendo a região da $12^{a}$ e $13^{a}$ costelas, o último local de deposição. Além disto, esta região é a que melhor representa a composição da carcaça 
BELTRAME, R.T., FERNANDES, D.R. e QUIRINO, C.R. Utilização do ultra-som em tempo real na avaliação da carcaça de pequenos ruminantes. PUBVET, Londrina, V. 5, N. 3, Ed. 150, Art. 1008, 2011.

como um todo. Informações sobre a gordura intramuscular, através da mensuração da marmorização da carne também têm sido descritos. Silva et al (2007) relatam que a mensuração do volume do músculo longisssimus também prediz com alta correlação a composição da carcaça. Dentre os estudos existentes, recentemente, a seleção de reprodutores realizada pela profundidade do músculo longissimus levou ao aumento da proteína total nas progênies, sugerindo um impacto positivo que a seleção para estes caracteres podem apresentar (HOPKINS et al., 2007 e 2008).

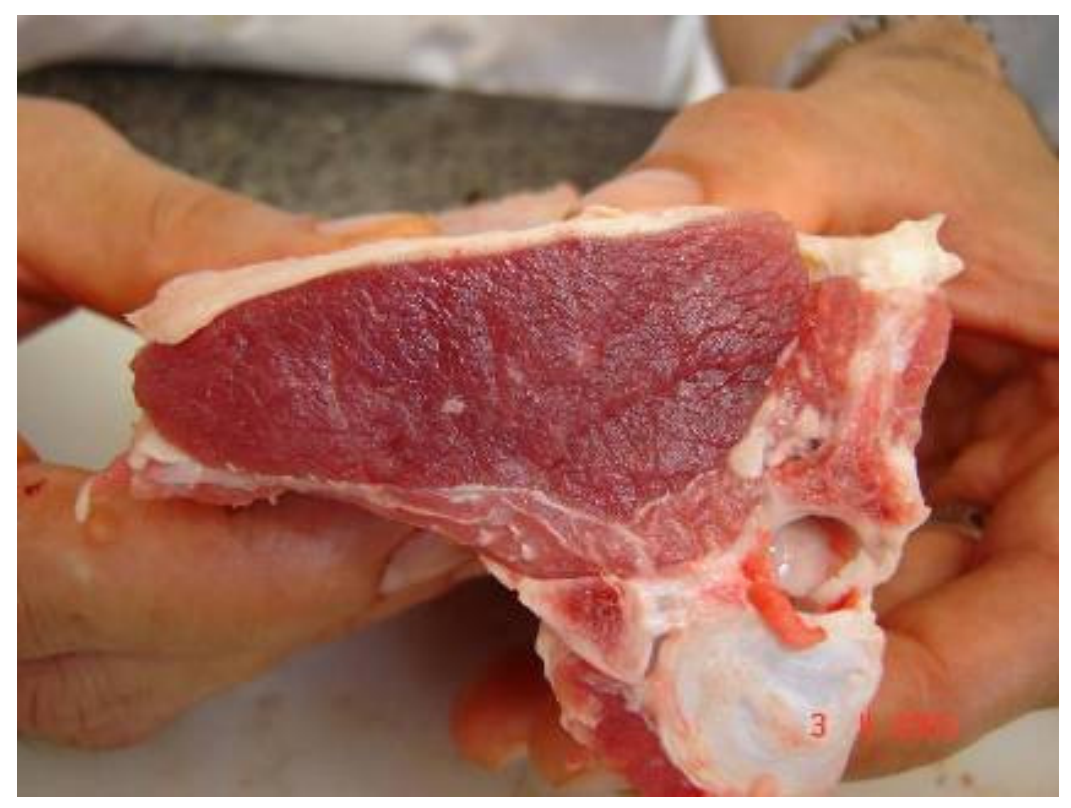

Figura 3. Músculo Longissimus toracicus et lumborum (Longissimus dorsi / olho de lombo) na carcaça ovina.

Trabalhos com ovinos já demonstram correlação de 0,75 e 0,55 entre as medidas ultra-sonográficas de AOL e EGS no músculo Longissimus e as mesmas medidas na carcaça (CARTAXO \& SOUSA, 2007). Suguisawa et al. (2003) salienta que na literatura os dados de correlação entre medidas de ultra-som e de carcaça apresentam grande variação e que a acurácia depende 
BELTRAME, R.T., FERNANDES, D.R. e QUIRINO, C.R. Utilização do ultra-som em tempo real na avaliação da carcaça de pequenos ruminantes. PUBVET, Londrina, V. 5, N. 3, Ed. 150, Art. $1008,2011$.

de diversos fatores, sobretudo da experiência do técnico, que influencia na qualidade e interpretação das imagens.

Embora o estudo em bovinos esteja avançado, em ovinos ainda não existe um padrão definido para as medidas de coleta, transdutores e freqüências a se utilizar. A mensuração dos caracteres acima descritos não é tão simples. O custo do equipamento somado a pequena dimensão da gordura subcutânea comparada a outras espécies, e a presença de lã ou pelo são as maiores dificuldades apresentadas. Embora não seja difícil a obtenção de uma imagem da área estudada (Figuras 4, 5 e 6), a análise das imagens posterior a mensuração no próprio ultra-som também parecem influenciar a qualidade dos resultados. Recomenda-se que as mesmas sejam analisadas em computador com auxílio de software especifico (POLIZEL NETO et al, 2009).

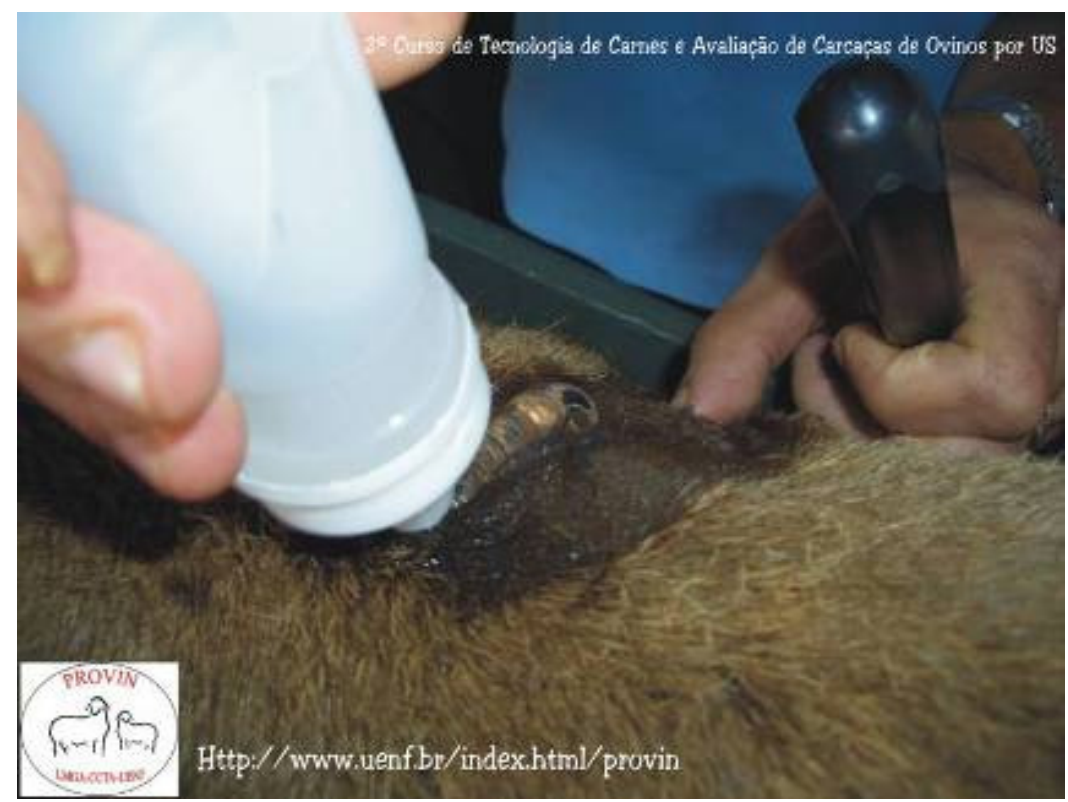

Figura 4. Utilização de gel em área tricotomizada para realização de ultrasonografia in vivo da carcaça ovina. 
BELTRAME, R.T., FERNANDES, D.R. e QUIRINO, C.R. Utilização do ultra-som em tempo real na avaliação da carcaça de pequenos ruminantes. PUBVET, Londrina, V. 5, N. 3, Ed. 150, Art. $1008,2011$.

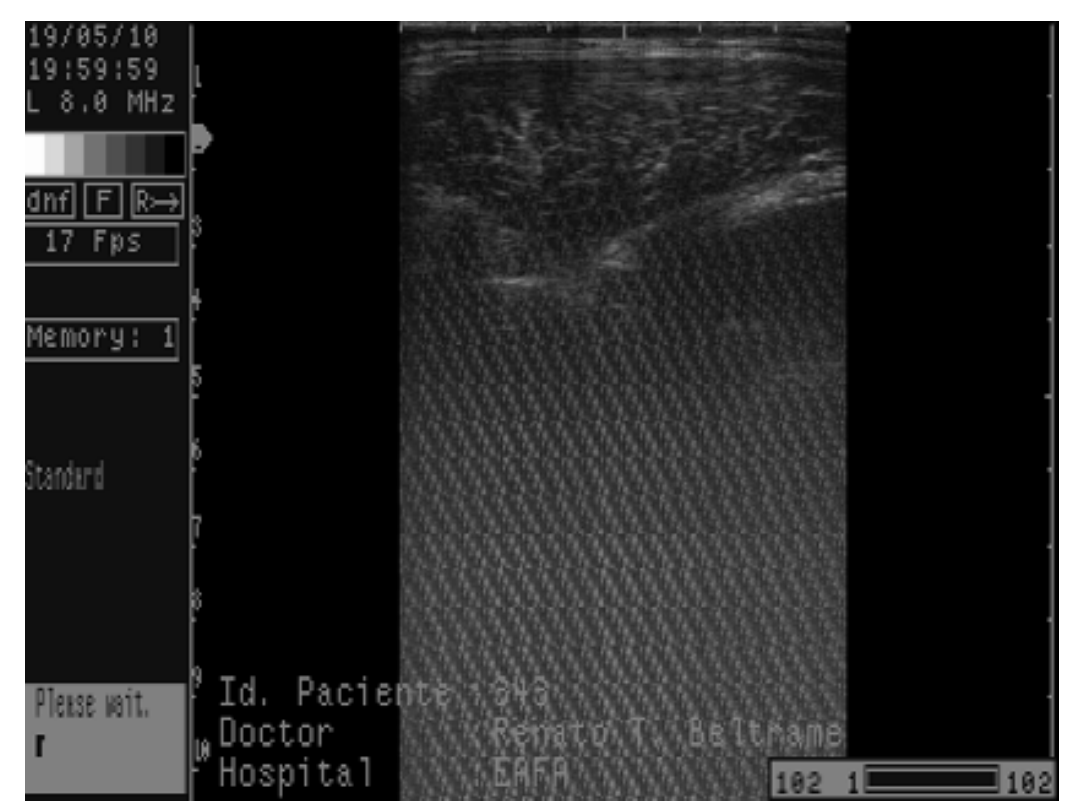

Figura 5. Imagem do músculo longissimus obtida com transdutor linear de 8 Mhz em ovino da raça Santa Inês.

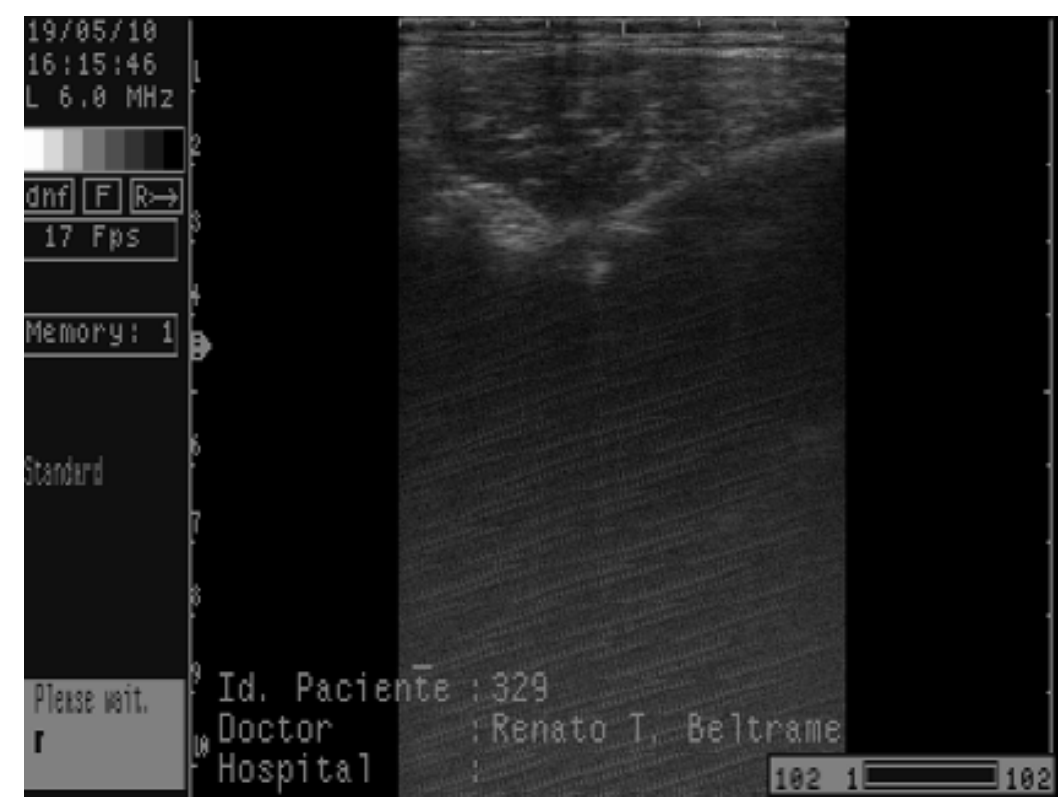

Figura 6. Imagem do músculo longissimus obtida com transdutor linear de 6 Mhz em ovino da raça Santa Inês.

De um modo geral, as informações ultra-sonográficas poderão complementar as avaliações realizadas rotineiramente em provas de ganho de 
BELTRAME, R.T., FERNANDES, D.R. e QUIRINO, C.R. Utilização do ultra-som em tempo real na avaliação da carcaça de pequenos ruminantes. PUBVET, Londrina, V. 5, N. 3, Ed. 150, Art. $1008,2011$.

peso e nos programas de seleção. Uma vez que sejam agregadas mais informações de desempenho dos animais haverá mais coerência no processo de decisão do produtor com reflexos positivos quanto ao atendimento dos objetivos dos sistemas de produção. A possibilidade de avaliação do potencial genético das fêmeas e a oportunidade de se avaliar amostras maiores e mais representativas de reprodutores, dentro de uma população são outros importantes benefícios da inclusão de dados de carcaça por ultra-sonografia nos programas de melhoramento genético de ovinos e caprinos.

\section{4 - Referencias Bibliográficas}

ARIAS, L.A.Q.; PABLO, C.D.; HERRADON, P.J.G.; MARTINEZ, A.I.P.; GONZALEZ, J.J.B. Ecografía y reproducción en la vaca. Universidade de Santiago de Compostela, Santiago de Compostela, 2006.

BREUKELMAN, S.P.; SZENCI, O.; BECKERS, J.F.; KINDAHL, H.; MULDER, J.H.; JONKER, F.H.; WEIJDEN, B.V.D.; REVY, D.; POGANY, K.; SULON, J.; NEMEDI, I.; TAVERNE, M.A.M. Ultrasonographic appearance of the conceptus, fetal heart rate and profiles of pregnancyassociated glycoproteins (PAG) and prostaglandin F2a-metabolite (PGF2a-metabolite) after induction of fetal death with aglepristone during early gestation in cattle. Theriogenology, $v$. 64, p. 917-933, 2005.

CARTAXO, F.Q, SOUSA, W.H. Correlações entre as características obtidas in vivo por ultra-som e as obtidas na carcaça de cordeiros terminados em confinamento. Revista Brasileira de Zootecnia, v.37, n.8, p.1490-1495, 2008.

CARR, M.A.; WALDRON, D.F.; WILLINGHAM, T.D.; Relationships among weights, ultrasound and carcass characteristics in Boer-cross goats. Sheep and Goat, Wool and Mohair CPR, p.55-59, 2002.

CARTAXO, F. Q. Efeitos do genótipo e da condição corporal sobre o desempenho, predição e avaliação de carcaça de cordeiros terminados em confinamento. 2006. 138 f. Dissertação (Mestrado em Zootecnia) - Universidade Federal da Paraíba, Areia, 2006.

DescôteauX, L.; GNemmi, G.; COLloton, J. Practical Atlas of Ruminant and Camelid Reproductive Ultrasonography., Blackwell Publishing, USA, 228 p, 2010.

FERNANDEZ, C.; GALLEGO, L.; QUINTANILLA, A. Lamb fat thikness and longissimus muscle area measured by a computerized ultrasonic system. Small Ruminant Research, v. 26, n. 3, p. 277-282, 1997.

FERNANDEZ, C. et al. Using ultrasonic to determine fat thikness and longissimus dorsi area on Manchego lambs of different live weight. Small Ruminant Research, v. 27, n. 3, p. 159-165, 1998. 
BELTRAME, R.T., FERNANDES, D.R. e QUIRINO, C.R. Utilização do ultra-som em tempo real na avaliação da carcaça de pequenos ruminantes. PUBVET, Londrina, V. 5, N. 3, Ed. 150, Art. $1008,2011$.

FERRI, S.T.S.; VICENTE, W.R.R.; TONIOLLO, G.H. Estudo da involução uterina por meio da ultra-sonografia (modo-B) em cadelas submetidas a cesariana. Arquivo Brasileiro de Medicina Veterinária e Zootecnia. v.55, n.2, p. 167-172, 2003.

GANAIE, B.A., KHAN, M.Z., ISLAM, R., MAKHDOOMI, D.M., QURESHI, S., WANI, G.M. Evaluation of different techniques for pregnancy diagnosis in sheep. Small Ruminant Research, v. 85, p. 135-141, 2009.

HAIBEL, G.K. Use of ultrasonography in reproductive management of sheep and goat herds. Veterinary Clinics of North America: Food Animal Practice., v.6, p.597-613, 1990.

HOPKINS, D. L., STANLEY, D. F., MARTIN, L. C., PONNAMPALAM, E. N., \& VAN DE VEN, R. Sire and growth path effects on sheep meat production. 1. Growth and carcass characteristics. Australian Journal of Experimental Agriculture, v. 47, p. 1119-1127, 2007.

HOPKINS, D.L., PONNAMPALAM, E.N., WARNER, R.D. Predicting the composition of lamb carcases using alternative fat and muscle depth measures.

Meat Science, v. 78, p. 400-405, 2008.

LANDIM, A.V. Desempenho e qualidade de carcaça em ovinos cruzados no Distrito Federal. 2005. 98 f. Dissertação (Mestrado em Ciências Agrárias) - Universidade de Brasília, DF, 2005.

NYLAND, T.G.; MATTOON, J.S. Ultra-som diagnóstico em pequenos animais. São Paulo, Roca, 2004.

SANTOS, M.H.B.S.; OLIVEIRA, M.A.L.; LIMA, P.F.; Diagnóstico de gestação na cabra e na ovelha. São Paulo, Varela, 2004.

POLIZEL NETO, A., JORGE, A, M., MOREIRA, P.S.A., GOMES, H.F.B., PINHEIRO, R.S.B., ANDRADE, E.N. Correlações entre medidas ultra-sônicas e na carcaça de bovinos terminados em pastagem. Revista Brasileira de Saúde e Produção Animal, v.10, n.1, p.137-145, jan/mar, 2009.

ROSA, G. T. et al. Determinação da área de olho de lombo e espessura de gordura de cobertura de cordeiros abatidos aos $30 \mathrm{~kg}$ de peso vivo através de ultra-sonografia. In: REUNIÃO ANUAL DA SOCIEDADE BRASILEIRA DE ZOOTECNIA, 42., 2005, Goiânia. Anais... Goiânia: SBZ, 2005. 1 CD-ROM.

SAINZ, R. D. Qualidade de carcaças e de carnes de ovinos e caprinos. In: REUNIÃO ANUAL DA SOCIEDADE BRASILEIRA DE ZOOTECNIA, 33, Fortaleza, 1996. Anais... Fortaleza:SBZ, 1996. p.3-14.

SILVA, S.R., GUEDES, C.M., SANTOS, V.A., LOURENÇO, A.L., AZEVEDO, J.M.T., DIAS DA SILVA, A. Sheep carcass composition estimated from Longissimus thoracis et lumborum muscle volume measured by in vivo real-time ultrasonography. Meat Science, v. 76, p. 708714, 2007.

SILVA SOBRINHO, A. G. Criação de ovinos, 2. Jaboticabal: Funep, 2001. 302 p.

STANFORD, K., JONES, S. D. M., \& PRICE, M. A. Methods of predicting lamb carcass composition: a review. Small Ruminant Research, v. 29, p. 241-254, 1998.

SUGUISAWA, L.; MATTOS, W.R.S.; OLIVEIRA, H.N.O.; Silveira, A.C.; Arrigoni, M.B.; Haddad, C.M.; Chardulo, L.A.L.; Martins, C.L. Ultrasonography as a predicting tool for carcass traits of Young bulls. Scientia Agricola, v.60, n.4, p.779-784, 2003. 
BELTRAME, R.T., FERNANDES, D.R. e QUIRINO, C.R. Utilização do ultra-som em tempo real na avaliação da carcaça de pequenos ruminantes. PUBVET, Londrina, V. 5, N. 3, Ed. 150, Art. 1008, 2011.

SUGUISAWA, L., MARQUES, A.C.W., BARDI, A., FAUSTO,D. Utilização da ultra-sonografia como ferramenta para padronização de carcaças comerciais. Tecnologia e Ciência Agropecuária, João Pessoa, v.3, n.4, p.55-65, 2009.

TAROUCO, J. U. Métodos de avaliação corporal in vivo para estimar o mérito da carcaça ovina. In: SIMPÓSIO INTERNACIONAL SOBRE CAPRINOS E OVINOS DE CORTE, 2., 2003, João Pessoa. Anais... João Pessoa: EMEPA, 2003. p. 443-449.

WOLF, A.; GABALDI, S.H. Acompanhamento ultra-sonográfico da gestação em grandes animais - parte I. Ciências Agrárias Saúde. FEA, Andradina, v. 2, n. 2, p.77-83, 2002. 